\title{
Entre continuidades e rupturas: uma investigação sobre o ensino e aprendizagem da História na transição do quinto para o sexto ano do Ensino Fundamental
}

\section{Between continuities and ruptures: an investigation on teaching and learning History in the transition from the fifth to the sixth grade in Elementary School}

\author{
Marlene Rosa Cainelli ${ }^{1}$
}

\begin{abstract}
RESUMO
Este artigo tem por objetivo apresentar algumas análises a partir das investigações realizadas por uma pesquisa em uma escola do Ensino Fundamental tendo como fundamentação teórica o campo da Educação Histórica. Buscamos perceber, a partir de observações da aula de História, como os alunos e o professor exteriorizam os principais desafios e dificuldades da transição da quarta série ( $5^{\circ}$ ano) para a quinta série $\left(6^{\circ}\right.$ ano). Neste trabalho, dialogamos com pesquisadores como Barca (2009), Malerba (2011), Schmidt (2009) e Rüsen (2010). Com isso, pudemos abordar questões que revelam qual a relação do professor com a teoria da história a partir de sua prática em sala de aula. Foram observadas também as abordagens e relações dos sujeitos - alunos e professor - com o conhecimento histórico, bem como as estratégias didáticas com relação ao uso do livro didático.

Palavras-chave: Educação Histórica; Ensino de História; conhecimento histórico.




\begin{abstract}
This article aims to present some analysis from the experience offered by a field research conducted in an Elementary School from the precepts of History Education. It is intended to discuss issues related to the school's fifth grade (6 years) from a public school, for example, the teaching strategies and the relationship of students with the knowledge of history. We search from observations of History lessons, as students and teacher externalize the main challenges and difficulties of the transition from fourth grade ( 5 years) for the fifth grade (6 years), based on these observations and the talking with researchers of Education and the Teaching of History Barca (2009), Malerba (2011), Schmidt (2009) e Rüsen (2010). With this we lift questions that reveal what relation has the fifth-grade teacher with the initial years. We also observed the relationship of subjects and approaches among themselves and with the historical knowledge and the teaching strategies with respect to textbooks.
\end{abstract}

Keywords: Historical Education, teaching History, historical knowledge.

A transição da quarta para quinta série ou sexto ano no Paraná é mediada por mudanças significativas para os alunos. O sentimento de terminalidade de uma etapa educacional é reforçado pelo modelo que impõe uma articulação Estado/município praticamente inexistente, tanto no âmbito administrativo como no pedagógico. As primeiras séries do ensino fundamental público são de responsabilidade dos municípios e as séries finais, assim como o ensino médio, ficam a cargo do Estado. Em que âmbito se constitui na prática esta passagem entre os níveis de ensino? Seria uma transição articuladora ou desarticuladora? Enquanto estruturas distintas, estes espaços não se articulam de forma a propiciar uma continuidade de propostas pedagógicas e caracterizam-se por serem redes de ensino distintas, o que dificulta o processo de transição do aluno da rede municipal para a estadual.

Entre os problemas que estudos detectam - desta falta de articulação entre os níveis de ensino - podemos citar os indicadores que medem o rendimento dos alunos na quinta série. Segundo dados de estudos do INEP ${ }^{2}$, esta seria responsável em média por $30 \%$ da distorção idade/série na continuidade do ensino fundamental, além de uma porcentagem grande de alunos que abandonam a escola.

${ }^{2}$ INEP- Instituto Nacional de Estudos e Pesquisas Educacionais. Um estudo sobre este assunto foi realizado por Aparecida Reis Barbosa em dissertação de Mestrado com o título A relação Estado/ municipio na passagem da $4^{a}$ para $5^{a}$ série em Curitiba, defendida no ano de 2008 na Universidade Federal do Paraná. 
Em nossa pesquisa, não tivemos como objetivo estudar as questões que envolvem as políticas públicas de educação, principalmente relativas ao binômio Estado/município, no que se refere ao fio condutor dos sistemas de ensino. No entanto, pudemos perceber, em entrevistas e observações com os sujeitos que na prática vivenciam o processo de transição de um sistema para outro, que trabalhos de parceria e continuidade são praticamente inexistentes.

A municipalização do ensino fundamental de $1^{\mathrm{a}}$ à $4^{\mathrm{a}}$ série no Paraná se inicia em meados da década de 50 do século XX. Este quadro se efetiva com a Lei 5.692/71 e culmina com a lei 9.394/9633. Estudiosos dividem a municipalização do ensino em três períodos:

O primeiro associado ao processo de constituição e de reestruturação do sistema estadual de ensino, implicado pelas leis e reformas nacionais de educação (1961 e 1971); o segundo desenvolve-se associado aos projetos nacional (1975-1981) e regional, com financiamento internacional, voltados à educação no meio rural, e o terceiro, inicia-se com os estudos nacionais de custo/aluno que, com as mudanças tributárias definidas na Constituição de 1988, passaram a funcionar como parâmetro para o modelo paranaense que vigorou de 90 a 97 (SANTOS, 2003, p. 263).

A ruptura que se processa de um sistema para outro se evidencia na forma como a municipalização se efetivou historicamente apenas na lógica administrativa e financeira dentro dos pressupostos de reconfiguração do Estado Brasileiro (BARBOSA, 2008). Na proposta de municipalização não estiveram presentes projetos de articulação entre Estados e municípios para as questões pedagógicas.

$\mathrm{O}$ aluno que transita de um sistema para outro inicia praticamente do zero uma nova vida escolar ao terminar o quinto ano, da escola municipal recebe o diploma que o considera apto a adentrar no sistema estadual de ensino no sexto ano e, na nova realidade, encontra um sistema que desconfia de sua formação e realiza diagnósticos para saber seu nível de aprendizagem. Esta relação de desconfiança entre as redes de ensino pode ser percebida nas falas de seus protagonistas - alunos e professores.

${ }^{3}$ A Lei 5.692/71 indica a "progressiva passagem para a responsabilidade municipal de encargo e serviços da educação, especialmente do $1^{\circ}$ grau, que pela sua natureza possam ser realizados mais satisfatoriamente pelas administrações locais" (Art. 58, parágrafo único).

Lei 9.394/96 - Art.11 - Os Municípios incumbir-se-ão de: [...] V - oferecer a educação infantil em creches e pré-escolas, e, com prioridade, o ensino fundamental, permitida a atuação em outros níveis de ensino somente quando estiverem atendidas plenamente as necessidades de sua área de competência e com recursos acima dos percentuais mínimos vinculados pela Constituição Federal à manutenção e desenvolvimento do ensino. 
Em nossa investigação, descobrimos que o percurso em torno da transição entre os níveis de ensino não envolve os professores e as escolas investigadas, ficando restrito à movimentação dos alunos que saem de um espaço para outro. A perspectiva da mudança aparece algumas vezes na fala de uma professora da quarta série, que utiliza a quinta série e a perspectiva do desconhecido para criar nas crianças um imaginário não muito atrativo com relação ao novo. Irritada com o barulho na sala de aula, ela dispara em direção aos alunos a seguinte frase: "vocês irão ver quando forem para a quinta série, lá vocês serão apenas um número, com vários professores que não irão saber nem o nome de vocês". Este retrato do ensino fundamental II é confirmado em outros momentos, quando a professora se refere ao fato de que eles não são mais crianças e logo estarão na quinta série, sendo agora os mais velhos da escola e tendo que ser exemplos para os mais jovens, principalmente na hora do recreio, contradição interessante que se espelha ao chegarem à quinta série no novo colégio, onde passam a ser os mais jovens, iniciando novamente o caminho em busca da maturidade.

A relação da aprendizagem da história no processo de transição da quarta para a quinta série esteve no centro de nossa investigação nos últimos dois anos. Pesquisamos como o aluno se relaciona com o conhecimento histórico nas séries iniciais e depois nas séries finais do ensino fundamental, tendo como hipótese principal uma diferença substancial na forma de ensinar história entre os níveis. Em nossa concepção, a formação específica do profissional de história determinaria uma especificidade na forma de ensinar história para crianças e na mobilização de conhecimentos históricos em direção à ciência da história.

As contradições não se resumem à maturidade perdida e se estabelecem em vários parâmetros, desde os conteúdos não aprendidos, as disciplinas demarcadas por horários e professores diferentes até as relações com os professores, que deixam a afetividade daqueles que tudo sabem sobre seu aluno para o professor que muitas vezes não sabe seu nome. Este movimento realizado pelo aluno, ora em retorno ora em direção a algo desconhecido para ele, fez com que percebêssemos algumas mudanças em seu comportamento.

Na passagem da quarta para a quinta série, acreditamos que os professores deveriam evidenciar práticas que permitissem o desenvolvimento de recursos pessoais dos alunos, até então não acionados, e que as aprendizagens do passado deveriam dialogar com as novas aprendizagens. Esta passagem é vista como um momento de dificuldades, pois os espaços e o ritmo de estudo são diferentes. Esta fase é descrita como uma época de transformações e desafios, especialmente para o aluno.

Como acompanhamos durante o primeiro ano sete alunos que saíram de uma escola municipal para uma escola estadual de ensino fundamental II e 
ensino médio, tivemos oportunidade de acompanhar sujeitos concretos e nominados em seu percurso escolar durante os anos de 2008, 2009 e 2010. Num primeiro momento nosso olhar se debruçou sobre como este aluno se relacionava com a escola e seu entorno, num segundo momento com a disciplina de história e, finalmente, com o professor e o material didático da disciplina.

O que buscamos nos indivíduos que pesquisamos? Nossa investigação se debruça sobre o professor das séries iniciais e sobre o professor das séries finais do ensino fundamental com a perspectiva de entender como a história é ensinada. Não buscamos identificar nestes profissionais perspectivas historiográficas impossíveis de serem detectadas, a não ser intuitivamente por estes. Nesse sentido, buscamos o que Rüsen chama de "trato reflexivo do homem com seu mundo" (RÜSEN, 2001). É a relação que este profissional tem com seu mundo que efetivamente determina a forma de ensinar história, são suas carências de orientação e seus critérios de sentido que dão forma ao conteúdo ensinado ou teoricamente pensado.

Aqui poderíamos nos reportar à França pós-revolucionária, onde, no Dicionário de Pedagogia de 1885, Ernest Lavisse escreve o verbete História, no qual observa aos professores: "Se não se tornar um cidadão compenetrado de seus deveres e um soldado que ama seu estandarte, o professor terá perdido tempo. Isso é o que deve dizer aos futuros mestres o professor de história da escola normal como conclusão de seu curso." (DOSSE, 2001, p. 18). Lembrando que é no livro de Lavisse que as crianças da escola pública aprenderão no século XIX "a história da nação, narrativa que conta batalhas heroicas nas quais muitos sacrificaram a vida pela pátria". Qual seria hoje o exigido do professor de História para com seus alunos, o que deveria ser entendido para que o mestre não perdesse seu tempo ao ensinar?

Segundo a professora Maria Auxiliadora Schmidt:

Aprender história significa contar a história, isto é, significa narrar o passado a partir da vida no presente. O principal objetivo é elaborar uma orientação relacionada com a construção da identidade de cada um e, também, organizar a própria atuação nas lutas e ações do presente, individual e coletivamente. (SCHMIDT, 2009, p. 37).

Nas observações realizadas no campo de pesquisa, o olhar do pesquisador se debruçou sobre as relações que estes profissionais apresentam sobre a história a ser ensinada e como estes operacionalizam esta tarefa. A observação das aulas de história nas séries iniciais se mostrou mais demorada e instigante, pois estes conteúdos nem sempre vinham marcados pela mensagem "agora abram os cadernos de História". O pesquisador precisava estar atento aos conteúdos 
para perceber, mesmo que a professora não anunciasse, que a aula poderia apresentar temas e conteúdos de história.

Um fator importante nas análises resultantes das observações e questionários realizados no campo de pesquisa diz respeito à formação de cada profissional. Fator decisivo, que não pode ser relegado, é que as professoras das séries iniciais não tiveram contato com a História ciência, visto sua formação em Letras e Pedagogia. O que faz com que tenhamos cuidado no tipo de confrontação entre os saberes com o professor da disciplina de História na quinta série. No entanto, se tivermos como pressuposto teórico a fundamentação de Rüsen para a questão, poderíamos afirmar que ao "narrar as experiências do passado humano de forma continuamente fundamentadas" (RÜSEN, 2001), mesmo os professores não formados em História se aproximariam daquilo que o autor chama de ciência da história.

Para este artigo, nos deteremos no professor da quinta série do ensino fundamental. Quem é este professor observado: formado em História há 17 anos na Universidade Estadual de Londrina, com especialização em História, leciona atualmente em duas escolas, uma particular e outra pública, nas seguintes séries: $5^{\mathrm{a}}$ série - Ensino Fundamental 2; $1^{\mathrm{a}}, 2^{\mathrm{a}}$ e $3^{\mathrm{a}}$ séries - Ensino Médio. Aqui apresentamos algumas discussões relativas tanto ao questionário respondido pelo professor como pelas observações realizadas por três estagiários do projeto durante os anos de 2009, 2010 e 2011.

Com relação à metodologia de pesquisa, nosso especial interesse se debruça tanto sobre quais os repertórios de conhecimento sobre a história este professor utiliza para ensinar história quanto a entender como, enquanto indivíduo, este faz suas escolhas e, ainda, como este professor vê a história com sentido para a vida dos seus alunos e para sua própria vida. Também pesquisamos quais os instrumentos metodológicos são mobilizados na experiência pedagógica de ensinar história.

Entendemos este professor de História como um indivíduo que, como qualquer outro, participa da história por estar envolvido em seu processo e, enquanto tal, tem carências de orientação e perspectivas de futuro. Como esta forma de se relacionar com o mundo em que vive interfere na sua forma de ensinar história? Temos inclusive como pressuposto que trabalhamos em nossa pesquisa também com professores que não são formados em História e, consequentemente, sua relação com a história é a mesma de qualquer indivíduo: a experiência, a tradição e o conhecimento didatizado, seja pela mídia, família, igreja ou pela escola.

As questões relativas à forma de abordagem do conteúdo histórico são muito importantes na pesquisa que realizamos. Nas observações, percebemos 
que a aula de História se concretiza por aquilo que está no texto, ou seja, no livro didático. É o livro didático que dita o ritmo da aula, os exercícios e o conhecimento histórico a ser ensinado. Refletindo sobre a organização das aulas do professor, encontramos inúmeras estruturações, mecanismos didáticos e de controle em sua metodologia; também observamos os posicionamentos com relação aos alunos e ao conteúdo com o qual ele trabalha. Entretanto, alguns destes procedimentos são mais recorrentes e podemos discuti-los teoricamente, à medida que já identificados em outros ambientes, já que se apresentam como práticas menos restritas em comparação a outras, que aparecem mais ligadas às particularidades da organização daquela sala em si. Para este trabalho, opta-mos por analisar a relação do professor com a utilização do livro didático de História e como este se insere no contexto da aula da $5^{\mathrm{a}}$ série A e $5^{\mathrm{a}}$ série $\mathrm{B}$ $\left(6^{\circ}\right.$ ano). O livro utilizado pela turma é Projeto Araribá - História 6 ( $5^{\mathrm{a}}$ série $6^{\circ}$ ano $)^{4}$.

Dentro da composição das aulas, as crianças manipulam bem o livro e este aparece como suporte textual. Nas observações, notamos que o professor poucas vezes escreve textos na lousa para que as crianças copiem ou traz textos para sala de aula. Geralmente utiliza os textos estruturados no livro, seguindo a organização cronológica deste no estudo das sociedades.

É em torno das informações organizadas neste livro que o professor estrutura a aula, pois, depois da leitura que eles realizam de forma individual e silenciosa - não chegamos a presenciar momentos de leitura compartilhada ou em voz alta -, o professor explica organizando as informações do livro na lousa. Essa atividade é bem ampla, envolvendo a sala toda. O professor coloca o título dos tópicos do livro que ele quer que os alunos copiem e vai perguntando as características do conteúdo que os alunos leram, compondo com essas respostas os tópicos que eles terão anotados em seu caderno e, assim, discutindo e acrescentando novas informações ou reformulando as colocações dos alunos que ele considera que tiveram uma compreensão parcial ou diferente do sentido que o livro expressa.

Nesse sentido podemos relacionar com o que nos diz Bittencourt:

[...] o livro didático é também um depositário de conteúdos escolares (grifo no original), suporte básico e sistematizador privilegiado dos conteúdos elencados pelas propostas curriculares; é por seu intermédio que são passados os conhecimentos e técnicas considerados fundamentais de uma sociedade em determinada época. (BITTENCOURT, 1998, p. 72).

${ }^{4}$ Editora Moderna, coleção Projeto Araribá. 
Para Rüsen (2010), diante da importância já comprovada por especialistas da utilização do livro no processo de ensino aprendizagem, é possível se pensar em um livro didático de história ideal. $\mathrm{O}$ autor afirma que um livro didático

[...] Deve oferecer explicações inteligíveis e verificáveis, sem se limitar, entretanto, a meras informações de fatos, bem como evitar por princípio argumentações monocausais e insistir no fato de que a interpretação histórica está aberta por princípio às argumentações multicausais. Assim, deve apresentar o conhecimento histórico de forma argumentativa e evitar qualquer aparência de uma certeza dogmática. (RÜSEN, 2010, p. 123).

Neste processo, podemos perceber que o professor faz do livro a figura central do processo de ensino-aprendizagem da história na sala de aula e as discussões e os conteúdos que os alunos anotarão partem do conhecimento e das características discutidas pelo livro didático. A partir dele, se estrutura a aula e a organização da discussão dos conhecimentos históricos acerca das sociedades estudadas.

É compreensível que o professor se sinta seguro ao utilizar um livro didático que ele supostamente avaliou e escolheu ${ }^{5}$, considerando-o como suporte suficiente para sua aula. Entretanto, entendemos que é possível e necessário problematizar a figura do livro, à medida que este ocupa dentro do ambiente escolar o papel de detentor do conhecimento, das informações e da verdade. É a partir dele que o professor fala e depois dele é que o professor se posiciona, para garantir que o que eles leram seja bem sistematizado de acordo com a organização construída na lousa durante a discussão com seus alunos.

Esta utilização do livro como detentor do conhecimento não se restringe ao momento de exploração e discussão dos conteúdos. O professor também pauta no livro muitas das atividades desenvolvidas durante a aula e, quando estas não são propostas pelo livro didático, são com consulta ao material didático e às anotações do caderno. Ou seja, o livro não só transmite o que eles precisam saber para discutir com o professor, mas também retoma e delimita as informações que eles devem reter. Até quando o professor traz uma atividade impressa de casa, esta dialoga com os textos informativos do livro didático e com seu vocabulário.

Esta dependência do texto escrito leva a situações como a observada por um dos pesquisadores. Durante a correção de um exercício, o professor já impaciente com a demora do exercício, responde para uma das alunas: " $A$

${ }^{5}$ Consideramos que o professor supostamente escolheu o livro didático que utiliza devido ao Programa Nacional do Livro Didático (PNLD), onde os professores das disciplinas têm a oportunidade de analisar e escolher os livros que usarão através do Guia do Livro Didático. 
resposta é de acordo com o texto não de acordo com sua cabeça." Vejamos que esta expressão desconstrói por completo a possibilidade da formação de um pensamento histórico. De acordo com Rüsen, "a referência do aprendizado à experiência não teria sentido didático se não fosse relacionada à subjetividade do aprendiz. O aprendizado histórico deve, assim, ser relacionado à subjetividade dos receptores, à situação atual do problema e à carência de orientação, de que parte o recurso rememorativo ao passado" (SCHMIDT; BARCA, MARTINS, 2010, p. 48).

Em nossa investigação, percebemos que no ensino de história na educação básica em muitos casos ainda se concretiza enquanto conhecimento histórico a perspectiva Ranqueana do século XIX, onde o "fato histórico é o ponto de chegada e de partida" (MALERBA, 2011) e a história ensinada é centrada nos acontecimentos. Este entendimento do fato se reflete principalmente quando imaginamos a necessidade de ensinar história a partir de um determinado evento localizado no tempo e no espaço, o que significaria que o evento ou o fato seria materializado concretamente. A forma de representação da História que se estabelece no livro didático utilizado pelo professor e, consequentemente, na forma como o professor ensina história, se traduz naquilo que Hyde Wite chama de história prefigurada, ou seja, a história ensinada na sala de aula está desde sempre já pré-formada (MALERBA, 2011).

Nesse sentido, podemos afirmar que o ensino de história em sala de aula narra acontecimentos, fatos já pré-demarcados e que aquilo que Koselleck argumenta que o acontecimento precisa ser visto como modalidade temporal não é percebido. O professor perde com isto a dimensão que "só com o mínimo de anterioridade ou posteridade se consegue a unidade de sentido que forma um acontecimento a partir dos incidentes" (KOSELLECK, 1993, p. 142).

Em outro momento, a questão dos conhecimentos prévios e da capacidade de o aluno fazer inferências baseado nas evidências colocadas pelo professor e pelo texto didático são desprezadas. Uma das questões do livro sobre a Mesopotâmia abordava o nascimento das estrelas, sob a visão dos mesopotâmios. $\mathrm{O}$ livro didático apresentava um texto que falava sobre a formação das estrelas, que viviam na terra e que se transportaram para os céus. Uma aluna responde que as estrelas viviam na terra e morreram e foram para o céu. O professor pergunta em que parte do texto está escrito que elas morreram? A aluna diz que não está no texto e que respondeu desta maneira porque para sair da terra e ir viver no céu é preciso morrer. O professor diz "que deve responder de acordo com o texto e não tirar conclusões dessa maneira".

Novamente a centralidade do texto didático chama a atenção no processo de ensino-aprendizagem tanto para as séries iniciais, onde o professor está 
refém de um conteúdo para o qual não tem formação, como para o professor especialista, que também está preso no texto didático como forma positivada de conhecimento, o que nos remete ao argumento de Rüsen (apud SCHMIDT; BARCA; MARTINS, 2010) que não vê possibilidade de uma aprendizagem histórica em "mera absorção de conhecimentos positivos sobre o passado".

Outro fator importante e que merece ser destacado é a forma como o livro didático sintetiza o conhecimento histórico a partir da narração de acontecimentos demarcados temporalmente e arbitrariamente escolhidos para representar a História da Humanidade ou a História pátria. Temos que ter em mente que "os eventos não são jamais apreendidos de maneira direta e completa, mas incompleta e literalmente, por meio de indícios e testemunhos" (MALERBA, 2011, p. 68). No caso do livro didático, a História se torna uma síntese explicativa que faz com que "um século caiba numa página" (MALERBA, 2011).

Outra atividade importante para exemplificar a metodologia do professor e a forma petrificada de abordagem do conhecimento histórico está em como os exercícios são corrigidos. O que é certo ou errado em se tratando do conhecimento histórico? A forma de correção dos exercícios é um capítulo muito interessante no processo ensino-aprendizagem, seja pelo desencadear de ideias não aproveitadas pelo professor, seja pela materialização da importância do livro como depositário do conhecimento histórico. A correção das questões propostas pelo professor segue, na maioria das vezes, um ritual comum a todas as salas de aula.

O professor pergunta quem fez a tarefa ou quem já terminou o exercício e escolhe alguém para responder a primeira questão. Feita a resposta, pergunta se alguém tem uma resposta diferente; caso aconteça de haver alguma resposta diferente, o professor decide qual a melhor resposta. Em alguns casos, a melhor resposta vai para o quadro pelas mãos do autor e em outros o professor, como símbolo máximo do saber, passa no quadro a resposta correta para que todos façam a cópia. Este ritual é carregado de significados para quem pensa a aprendizagem da história no sentido da formação do pensamento histórico. Toda e qualquer discussão feita anteriormente, mesmo que tenha sido carregada de subjetividade e participação dos alunos, é anulada no momento em que a resposta correta é demarcada no quadro ou no ditado do professor.

Nesse sentido, a subjetividade presente na fala dos alunos é descartada. Apesar da ideia do professor de que este exercício de pergunta e resposta se constitua em um diálogo, para o professor este suposto diálogo acontece como forma de motivação para atingir um determinado objetivo, seja para corrigir o exercício ou para iniciar um conteúdo novo. 
Entre os principais fundamentos deste olhar historiográfico para o ensino de história está a importância do pensamento histórico para este processo. Autores como Rüsen (1997, 2001), Lee (2001, 2003) e Schmidt (2009) argumentam que, para se investigar a aprendizagem histórica, é preciso ter como referência teórica e metodológica a ciência da História. Nesta pesquisa que realizamos, discutimos como os conteúdos da história ensinada são determinados e postos em prática em sala de aula. A seleção e a definição de conteúdos escolares pressupõem uma determinada concepção de história além das demandas relacionadas aos poderes constituídos. Segundo Eric Hobsbawm, "todo estudo histórico, portanto, implica uma seleção minúscula, de algumas coisas da infinidade de atividades humanas do passado, e aquilo que afetou essas atividades. Mas não há nenhum critério geral aceito para se fazer tal seleção. (HOBSBAWM, 1998, p. 71.)

Entendemos que o desenvolvimento do pensamento histórico precisa ser objeto do ensino de história desde os anos iniciais do Ensino Fundamental e é preciso desenvolver o pensar historicamente, que pode ser evidenciado nas formas como os indivíduos entendem o conhecimento histórico. Não colocamos em oposição os conteúdos históricos baseados em eventos, datas e fatos e uma aprendizagem da história baseada no desenvolvimento do pensamento histórico. O que defendemos é uma estreita articulação na narrativa histórica que permita entender a relação que os sujeitos têm com os conceitos, ideias, conteúdos, cuja referência é a própria epistemologia da história. (SCHMIDT; GARCIA, 2006, p. 64).

A utilização do livro didático e a seleção de conteúdos já determinados fazem com que o professor priorize certas habilidades ou operações mentais de cunho mais didático do que relacionadas ao pensamento histórico. O conteúdo é dado de forma fragmentada e a subjetividade da aprendizagem do pensamento fica perdida. É necessário que a escolha de conteúdos recaia sobre a ciência da história como categoria fundamental, priorizando como método a importância da narrativa. A maneira como hoje o professor sugere o registro do conhecimento histórico acaba por provocar uma separação entre as formas de aprender a pensar e as formas de pensar com e a partir da história, ou seja, entre a aprendizagem e seu objeto. (GRENDHEL, 2009).

Rüsen (1993) indica muito bem o sentido de ensinar história hoje e como esta nova forma de pensar a aprendizagem da história interfere na forma de escolha dos conteúdos a serem trabalhados em sala de aula. O autor é enfático quando afirma que ensinar história como algo pronto e acabado, com conteúdos predefinidos e sem levar em conta o contexto e os sujeitos envolvidos no processo de ensino aprendizagem, pode levar a um ensino que não desenvolve 
o que é mais importante enquanto função do ensinar história, que é orientar os problemas da vida prática.

\section{REFERÊNCIAS}

BARCA, Isabel. Investigação em Educação Histórica: possibilidades e desafios para a aprendizagem histórica. In: . Atas das VI Jornadas Internacionais de Educação Histórica: Perspectivas de Investigação em Educação Histórica. v. 1. Curitiba: Ed UTFPR, 2007. p. 26-42.

BITTENCOURT, Circe. Livros didáticos entre textos e imagens. In: (Org.). O saber histórico em sala de aula. São Paulo: Contexto, 1998.

GRENDHEL, Marlene Terezinha. De como a didatização separa a aprendizagem histórica do seu objeto: um estudo a partir da análise de cadernos escolares. Tese (Doutorado em Educação) - Universidade Federal do Paraná: Curitiba, 2009.

HOBSBAWN, Eric. Sobre a História. São Paulo: Companhia das letras, 1998.

KOSELLECK, Reinhart. Futuro passado. Para una semántica de los tiempos históricos. Barcelona: Paidós, 1993

LEE, Peter. Progressão da compreensão dos alunos em história. In: BARCA, I. Perspectivas em educação histórica. Actas das Primeiras Jornadas Internacionais de Educação Histórica. Braga: Centro de Estudos em Educação e Psicologia, Universidade do Minho, 2001. p. 13-27.

"Nós fabricamos carros e eles tinham que andar a pé": compreensão da vida no passado. In. BARCA, I. Educação Histórica e Museus. Actas das II Jornadas Internacionais de Educação Histórica. Braga (Portugal): Universidade do Minho, 2003.

MALERBA, Jurandir. Ensaios: teoria, história e ciências sociais. Londrina: Eduel, 2011.

RÜSEN, Jörn. Studies in metahistory. Trad. Marcio E. Gonçalves. Pretoria: Human Sciences Research Council, 1993. 
. El libro de texto ideal: reflexiones en torno a los medios para guiar las clases de Historia. Revista Nuevas fronteras de la historia, Barcelona: Graó, n. 12, año IV, abr. 1997.

. Razão histórica. Teoria da história: fundamentos da ciência histórica. Trad. Estevão de Rezende Martins. Brasília: Editora Universidade de Brasília, 2001.

SANTOS, Jussara Maria Tavares Puglielli. A municipalização do ensino no Estado do Paraná: história, herança e desafio. In: GOUVEIA, Andréia Barbosa; SOUZA, Ângelo Ricardo (Org.). O financiamento da educação e o FUNDEF no Paraná. Curitiba: UFPR, 2001.

SCHMIDT, Maria Auxiliadora. Cognição histórica situada: que aprendizagem histórica é esta? In: BARCA, Isabel; SCHMIDT, Maria Auxiliadora (Orgs.). Aprender História: perspectivas da Educação Histórica. Ijuí: Editora Unijuí, 2009. p. 21-51.

; GARCIA, T. B. O trabalho com objetos e as possibilidades de superação do sequestro da cognição histórica: estudo de caso com crianças nas séries iniciais. In: (Orgs.). Perspectivas de investigação em Educação Histórica. Atas das VI Jornadas Internacionais de Educação Histórica. Curitiba: Editora UTFPR, 2006. p. 52-67.

; BARCA, Isabel; MARTINS, Estevão de Rezende (Orgs.). Jörn Rüsen e o ensino de História. Curitiba: Ed. UFPR, 2010.

Recebido em 18 de maio de 2011.

Aprovado em 12 de setembro de 2011. 
